Cross sectional study

Patient participation in surgical treatment decision-making can be measured using a 16-item scale with four distinct dimensions

\author{
$10.1136 /$ eb-2014-101830
}

\section{Carole Doherty}

Department of Health Care Management and Policy, University of Surrey, Guildford, Surrey, UK

Correspondence to: Dr Carole Doherty, Department of Health Care Management and Policy, University of Surrey, Guildford, Surrey GU2 7XH, UK; c.doherty@surrey.ac.uk

Commentary on: Heggland LH, Mikkelsen A, Øgaard T, et al. Measuring patient participation in surgical treatment decisionmaking from healthcare professionals' perspective. J Clin Nurs 2014;23:482-91.

\section{Implications for practice and research}

- It should not be assumed that all patients want to be actively involved in decision-making.

- To enhance our understanding of patient participation and to support its implementation in practice, ethnographic research with patients, including interviews and observations, is required.

- An exploration of the sphere of informed consent is also required with a view to framing defensible decision-making in this complex area of practice.

\section{Context}

This paper describes and tests an instrument designed to measure clinicians' perceptions of how they involve patients in surgical treatment decision-making. The researchers argue that in the context of the various forms of 'new public management' reforms in the EU, there has been a shift in policy towards recognising the importance of involving patients in treatment decision-making. However, the concept of patient participation remains vague. The paper aims to validate an instrument to examine this issue and to compare and contrast the perceptions of doctors and nurses in a Norwegian hospital.

\section{Methods}

This quantitative study used a cross-sectional self-completion survey to collect data. The instrument was developed from a qualitative study which identified four dimensions of patient participation in treatment decisions: information dissemination, formulation of options, integration of information and control. ${ }^{1}$ The instrument was tested on a total of 451 clinicians (119 doctors and 330 nurses-two respondents did not provide details of their occupation), giving an overall response rate of 73\% (92\% and 72\% for doctors and nurses, respectively). Data were analysed for validity and reliability using various statistical tests. Cronbach's $\alpha$ was above 0.66 for each item, suggesting that the questionnaire's internal consistency and reliability were adequate.

\section{Findings}

Empirical testing of this instrument looked to demonstrate a reasonable level of construct validity and reliability. Overall, it appeared that surgeons and nurses were supportive of patient participation in decisionmaking. Surgeons appeared to be more positive than nurses about patient involvement. However, the only dimension that was statistically significant (0.001) was integration of information, which could be accounted for by the relatively small sample sizes.

\section{Commentary}

This study's stated aim was to test and validate an instrument measuring patient participation in surgical treatment decision-making from the perspective of clinicians. What the study actually did was measure clinicians' self-reported perceptions of their willingness to provide patients with information and choice over aspects of their management. Patient participation in decision-making is generally viewed positively; therefore, these results are likely to contain social desirability bias as clinicians will respond in a manner that puts them in a positive light.

The items used wording such as "I provide" and "I ensure", suggesting active clinicians and passive patients. Two of the items begin "patients are told," which again is not suggestive of active patient participation. What is known from the patients' perspective is that patients feel a need to trust their doctors' expert judgement and sometimes want decisions made for them, as this quote from one surgical patient indicates: "The anaesthetist asked me which was my preference, of anaesthesia [...] There's no way I know whether a mask on your face or a needle in your arm or one up your backside, [or] whatever [is better], I have no idea!" ${ }^{2}$

In addition, the authors correctly point out that legally the consultant surgeon or anaesthetist has the final authority and responsibility. Adopting a passive role, patients are able to rely on the law of negligence to protect them if the medical treatment falls below the standard of a reasonably prudent doctor. ${ }^{3}$ When adopting a more active role, patients arguably assume responsibility for their own care and with this assumption comes the possibility of legal protection being diluted, meaning the patient risks contributing to negligence or having their actions judged as a new intervening action which relieves the clinician of liability. ${ }^{4}$

Competing interests None.

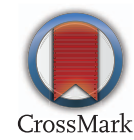

\section{References}

1. Heggland LH, Hausken K. A qualitative identification of categories of patient decision making by health care professionals and patients during surgical treatment. Clin Nurs Res 2012;22:206-27.

2. Doherty C, Saunders MNK. Elective surgical patients' narratives of hospitalization: the co-construction of safety. Soc Sci Med 2013;98:29-36.

3. Samanta A, Mello MM, Foster C, et al. The role of clinical guidelines in medical negligence litigation: a shift from the Bolam Standard? Med Law Rev 2006;14:321-66.

4. Herring JJW, Foster C. Blaming the patient: contributory negligence in medical malpractice. Professional Negligence 2009;25:76-90. 